\title{
Proceeding
}

Supplementary Issue: Spring Conferences of Sports Science. Costa Blanca Sports Science Events, 19-20 June 2020. Alicante, Spain.

\section{Autism spectrum disorder and physical activity}

\author{
FIORENZO MOSCATELLI ${ }^{1}$, RITA POLITO ${ }^{1}$, ALBERTO AMETTA ${ }^{2}$, MARCELLINO MONDA ${ }^{3}$, ANTONIETTA \\ MESSINA ${ }^{3}$, FRANCESCO SESSA ${ }^{1}$, AURORA DANIELE ${ }^{4}$, ANNA VALENZANO ${ }^{1}$, GIUSEPPE CIBELLI', \\ VINCENZO MONDA 3 \\ ${ }^{1}$ Department of Clinical and Experimental Medicine, University of Foggia, Italy \\ ${ }^{2}$ Department of Economy, University of Foggia, Italy \\ ${ }^{3}$ Department of Experimental Medicine, Section of Human Physiology and Unit of Dietetic and Sport Medicine, \\ University of Campania Luigi Vanvitelli, Naples, Italy \\ ${ }^{4}$ Department of Biological and Pharmaceutical Environmental Sciences and Technologies, University of Campania \\ Luigi Vanvitelli, Naples, Italy
}

\begin{abstract}
Autism is a common developmental disorder characterized by difficulties with speech and behaviours, such as lack of social abilities and repetitive behaviours. Some studies have shown that after the intervention of physical activity, all of the social interaction ability, communication ability, stereotyped behaviour and sports skills of children and adolescents with autism have been improved, which can reduce the degree of autism. The prevalence of autism spectrum disorder (ASD) has increased dramatically and is currently estimated at 1 in 68 children. ASD is defined by two symptom dimensions including social impairments and circumscribed and repetitive behaviours and interests (American Psychiatric Association). One subgroup that has increased is those with ASD without intellectual disability who currently comprise $68 \%$ of those diagnosed. Current guidelines recommend that youth engage in $\geq 60$ minutes of Physical Activity daily, with the majority being moderate-to-vigorous, and muscle strengthening activities $\geq 3$ days per week. Despite the significant need, few exercise programs have been developed or adapted for children with ASD, and there is a lack of evidence-based exercise treatments. Recommendations for improving exercise intervention studies in ASD include testing of treatments in function-ally-homogeneous (narrower) subgroups with ASD using larger wellcharacterized samples. This is necessary as children with ASD have different tolerances for activities/tasks and functional heterogeneity will likely lead to variable treatment responsiveness. Additionally, group-based treatments will be more applicable for children with ASD without intellectual disability.

Keywords: Autism spectrum disorder (ASD); Physical activity; Exercise intervention; Coaching in ASD; Therapeutic physical exercise.

Cite this article as:

Moscatelli, F., Polito, R., Ametta, A., Monda, M., Messina, A., Sessa, F., Daniele, A., Valenzano, A., Cibelli, G., \& Monda, V. (2020). Autism spectrum disorder and physical activity. Journal of Human Sport and Exercise, 15(3proc), S787-S792. doi:https://doi.org/10.14198/jhse.2020.15.Proc3.29

Corresponding author. Department of Experimental Medicine, Section of Human Physiology and Unit of Dietetic and Sport Medicine, University of Campania Luigi Vanvitelli, Naples, Italy.

E-mail: v.latorella@studenti.unisa.it

Supplementary Issue: Spring Conferences of Sports Science. Costa Blanca Sports Science Events, 19-20 June 2020. Alicante, Spain.

JOURNAL OF HUMAN SPORT \& EXERCISE ISSN 1988-5202

(c) Faculty of Education. University of Alicante

doi:10.14198/jhse.2020.15.Proc3.29
\end{abstract}




\section{INTRODUCTION}

Autism is a common developmental disorder characterized by difficulties with speech and behaviours, such as lack of social abilities, repetitive behaviours, communication disorders, activity and interest disorders with limitations [1]. The disease mainly occurs in children and adolescents, but the explicit age limits of children and adolescents haven't been decided. Based on the degree of individual cognition and socialization, Zhang Wenxin divides the kids under 12 years old into children and kids between 13 and 22 years old into adolescence [2]. According to the latest data from the Centers for Disease Control and Prevention, the prevalence rate of autistic children is $1 / 59$. And the data from Asia, Europe and North America reports an average prevalence of 1-2\% [3]. According to the report on the development of Chinese autistic children released by China on 17 October 2014, the prevalence of autism in China is similar to that in other countries in the world, with about $1 \%$. It can be seen that autism has become a public health problem that seriously affects the health of children and adolescents.

In addition to the core symptoms of social interaction, communication, and stereotyped behaviour, the motor skills of autistic patients are usually stunted [4]. Physical activity refers to all kinds of physical actions that consume energy due to skeletal muscle contraction, including physical exercise, work, housework, entertainment and other activities [5]. However, due to social and behavioural defects, autistic patients usually show a decline in physical activity level. Fewer opportunities for physical activity are more likely to affect their behaviour [6], and cause some chronic diseases, such as obesity, which is very common in autistic patients [7]. It has been reported that physical activity has a good intervention effect on autistic patients [8], and the physical and mental health of autistic patients contains the improvement of core symptoms [9]. Some studies have shown that after the intervention of physical activity, all of the social interaction ability [10-12], communication ability [11,13-15], stereotyped behaviour $[11,16]$ and sports skills $[11,17-19]$ of children and adolescents with autism have been improved, which can reduce the degree of autism $[14,15,20,21]$. These studies show that physical activity is very effective in intervention of children and adolescents with autism.

Although a large number of studies have shown that physical activity is effective in the intervention of children and adolescents with autism, the results of individual studies may still be uncertain due to the great differences in sample size, intervention means, intervention time, intervention frequency and measurement results in various studies.

\section{PHYSICAL EXERCISE IN ASD}

As described above, ASD and FXS exhibit various clinical features including mental retardation and epileptic episodes [22, 23]. Recently, numerous studies have focused on understanding the pathophysiological mechanisms responsible for ASD and FXS, and on developing more effective therapeutic treatments. Sairanen M et al. [24] reported that ASD is characterized by structural defects that include a reduction in forebrain volume and disruption of the neural network between the limbic system and other cerebral cortex regions. In addition, recent study demonstrated that ASD children presented an abnormal gait compared with that of age- matched controls, they showed a reduction in cadence, gait velocity, step length, and an increase in step width [25]. Interestingly, therapeutic physical exercise in patients with ASD increases hippocampal volume and promotes the robust growth of newly proliferated and/or differentiated cells by increasing brainderived neurotrophic factor (BDNF) in the cerebral cortex [26]. Also, the fmr1 gene was shown to play a critical role in the neural plasticity of dendritic spines in studies on neuropsychological function in ASD and FXS. Therefore, the absence of FMR results in dysmorphology and dendritic spine dysfunction [27, 28]. In addition, FMR1 knockout mice swim significantly slower than controls and take more time to arrive at the 
target platform in the Morris water maze [29]. Therapeutic physical exercise plays a critical role in neuronal cell survival in ASD patients and forced aerobic exercise during light photoperiods promotes vascularization and neurogenesis [30, 31]. Therapeutic physical exercise facilitates the pro-duction of neurotrophic factors, including nerve growth factor (NGF), fibroblast growth factor-2 (FGF-2) as well as BDNF, that improve neuropsychological function in infants with $\operatorname{ASD}[32,33]$. In a previous study using the valporic acid (400 $\mathrm{mg} / \mathrm{kg}$ )-induced ASD animal model, the animals with intervention of physical exercise showed incremental improvement in spatial learning memory, decision making, and neurogenesis in the hippocampal region via stimulating the PI3 KIAkt/ERK signalling pathway [34-38]. Moreover, exercise that combines physical and mental activities has improved cognitive ability in individuals with ASD, and participation of people with ASD in these activities serves the additional purpose of decreasing stereotypes [35, 36]. Strikingly, a recent report suggested that a mind-body exercise program could positively affect neural functional connectivity and memory processing and could therefore enhance memory function in individuals with ASD [39-44].

\section{SUPPORTING AND COACHING IN ASD}

Children with autism spectrum disorder (ASD) may experience challenges across most International Classifications of Functioning (ICF) activities and participation domains: learning and applying knowledge, general tasks and demands (e.g., following routines, handling stress, responding to demands), communication, self-care (e.g., getting dressed), domestic life (e.g., chores), interpersonal interactions and relationships, major life areas (e.g., school), and community life (e.g., recreation and leisure) [39]. Some of these challenges (e.g., communication and interpersonal relationship) are core impairments of the condition and are part of the diagnostic criteria for ASD [40]. Other difficulties (e.g., learning and self-care) are not part of diagnostic criteria, but are the daily life challenges resulting from the symptoms of ASD. These challenges negatively affect not only the quality of life of the child with ASD, but also that of their family [45-47]. Numerous interventions have been designed, empirically evaluated, and clinically implemented to remediate the underlying impairments experienced by children with ASD with various degrees of success [48-52]. Often, however, the most important barriers to participation are not impairments, but rather the context in which an activity takes place, such as people's attitudes, the physical environment, institutional policies, and human support [44]. In fact, remediating the skills of children with ASD without consideration of contextual issues typically leads to poor skill generalization [45-52]. Intervention is needed that accommodates a person's impairments and modifies the environment and task demands to yield faster, greater, and more meaningful changes than intervention focused on skill remediation alone [46, 47-54]. Intervention focused on enhancing the participation of children with ASD has the potential to increase their quality of life and that of their family [55-60].

By their nature, enhancing engagement in ICF activities and participation domains require an interprofessional perspective, because these hinge on a child with ASD using a variety of skills that are traditionally addressed by different health professionals. For example, playing team sports requires communication, self-regulation, and social-cognitive and motor skills [61-66]. Consequently, the involvement of several professions is critical to effectively address the participation needs of children with ASD and their families.

Effective interprofessional practice requires collaboration from individuals of different professional backgrounds with families and their children to address their needs [67-73]. Family-driven practice involves families having the primary decision making role in all aspects of care including setting goals and designing, implementing, and evaluating their child's intervention plan [74-79]. Culturally responsive practice includes understanding a person's beliefs for the medical condition they experience, recognizing their cultural identity, 
developing a trusting relationship, and using strengths-based approaches [80-84]. The CinC process combines 2 empirically supported interventions: coaching (a type of parent-mediated intervention) and context therapy to enhance the participation [85-90].

Goals of those with ASD and their family. The CinC process begins with identification of family-selected participation goals and continues with family-selected and implemented strategies to realize progress toward these goals [91-93]. The selected strategies prioritize modifying the task and environmental demands of an activity, rather than skill remediation. One of the interprofessional team members serves as coach to the family while collaborating with colleagues from other professions as the need arises based on a family's interest and readiness.

\section{CONCLUSION}

ASD is a complex neurobehavioral syndrome and no specific causes have yet been identified. Anatomical brain abnormalities, genetic anomalies, and neurochemical dysfunctions of various neurotransmitters and neuropeptides including GABA and glutamate, serotonin, dopamine, $\mathrm{N}$-acetyl aspartate, oxytocin, argininevasopressin, melatonin, vitamin $\mathrm{D}$, orexin, opioids, and acetylcholine contribute to the onset of autism. Our review suggests the important role played by altered neurotransmission in the etiopathogenesis of ASD. It is clear that many pathways are involved in determining autism, but how these biological systems interact with each other remains obscure. Further neurochemical network studies on early neurodevelopment alterations are required. Advancing the understanding of the etiology of the ASD mechanisms represents a real challenge, mainly due to the enormous heterogeneity of ASD. The evidence gathered by our review supports the existence of several dysregulated neurotransmitters and neuropeptides in animal models and in patients with autism. Although there is some evidence suggesting that specific receptor anomalies lead to specific phenotypic variations it is very hard to highlight the pathogenetic role of every neuronal receptor in determining the autism phenotype.

Accumulating evidence has shown that physical exercise interventions could be a valuable alternative to the existing behavioural therapies, as it was observed that acute physical exercises can improve cognitive functions, at least transiently, in ASD children [52]. Likewise, previous studies also showed that long-term physical exercise interventions had positive effects on executive functions among school-aged children who were diagnosed with ASD [53]. Moreover, it is reported that in children with ASD, the rehabilitative effects of physical exercise interventions (e.g., exergaming and Karate techniques training) on social communication, repetitive behaviours, and cognitive performance and be maintained, at least, up to one month after the cessation of the intervention [54].Notably, previous studies on physical exercise intervention focused on school-aged children with ASD, rather than pre-schoolers. As it is well-known that preschool age is a critical period for dramatic growth and the development of executive functions [55], thus it would also be appropriate to start intervention programs during this developmental stage. This assumption is supported by the growing evidence suggesting that early intensive interventions would ameliorate symptoms of ASD children, which was associated with an increased likelihood of moving into socialized environments in later life periods [56]. Collectively, physical exercise interventions that start at a preschool age stage seem to also be beneficial for this special population. 


\section{REFERENCES}

Bahrami, F.; Movahedi, A.; Marandi, S.M.; Sorensen, C. The Efect of Karate Techniques Training on Communication Deficit of Children with Autism Spectrum Disorders. J. Autism Dev. Disord. 2016, 46, 978-986. https://doi.org/10.1007/s10803-015-2643-y

Centre for Disease Control and Prevention (CDC). Data \& Statistics on Autism Spectrum Disorder (ASD). 2018. Available online: https://www.cdc.gov/ncbddd/autism/data.html (accessed on 1 January 2020)

Cristian V Francavilla, Francesco Sessa, Monica Salerno, Giuseppe D Albano, Ines Villano, et al. Influence of Football on Physiological Cardiac Indexes in Professional and Young Athletes. Front Physiol. 2018; 9:153. https://doi.org/10.3389/fphys.2018.00153

Eyman M, Cefaliello C, Mandile P, Piscopo S, Crispino M, Giuditta A. Training old rats selectively modulates synaptosomal protein synthesis. J. Neurosci. Res. 2013. 91:20-29. https://doi.org/10.1002/jnr.23133

Fournier, K.A.; Hass, C.J.; Naik, S.K.; Lodha, N.; Cauraugh, J.H. Motor Coordination in Autism Spectrum Disorders: A Synthesis and Meta-Analysis. J. Autism Dev. Disord. 2010, 40, 1227-1240. https://doi.org/10.1007/s10803-010-0981-3

Francavilla VC, Bongiovanni T, Genovesi F, Minafra P, Francavilla G. Localized bioelectrical impedance analysis: how useful is it in the follow-up of muscle injury? A case report. MED SPORT 2015; 68:32334.

Francavilla VC, Bongiovanni T, Todaro L, Di Pietro V, Francavilla G. Probiotic supplements and athletic performance: a review of the literature. MED SPORT 2017;70: 000-000. https://doi.org/10.23736/S0025-7826.17.03037-X

Francavilla C, Bongiovanni T, Todaro L, Genovesi F, Francavilla G. Risk factors, screening tests and prevention strategies of muscle injuries in elite soccer players: a critical review of the literature. Med Sport 2016; 69: 134-50

Francavilla G, Francavilla C. Physical exercise is therapy. MED SPORT 2013;66:625-8.

Francavilla C, Francavilla A, Braschi M, et al. Physical exercise and sport activities in patients with and without coronary heart disease. Monadi Arch Chest Dis 2007; 87-95.

Francavilla C, Vitale F, Ciaccio Marcello et al. Use of saliva in alternative to serum sampling to monitor biomarkers modification in professional soccer players. Frontiers in Phsiology, 2018. https://doi.org/10.3389/fphys.2018.01828

Gabriels, R.L.; Pan, Z.X.; Dechant, B.; Agnew, J.A.; Brim, N.; Mesibov, G. Randomized Controlled Trial of Therapeutic Horseback Riding in Children and AdolescentsWith Autism Spectrum Disorder. J. Am. Acad. Child. Adolesc. Psychiatry 2015, 54, 541-549. https://doi.org/10.1016/j.jaac.2015.04.007

Giuditta A, Chun JT, Eyman M, Cefaliello C, Bruno AP and Crispino M. Local gene expression in axons and nerve endings: the glia-neuron unit. Physiol. Rev. 2008. 88:515-555. https://doi.org/10.1152/physrev.00051.2006

Jiang, F.; Xu, D.Q. Study on Influences of Sports on Autistic Children-An Example of Service Center for Disabled in Ningxin Yangguang Jiayuan of Nanjing City. Sichuan Sports Sci. 2018, 37, 51-54.

Mazzeo F, Motti ML, Messina G, et al. Use of nutritional supplements among south Italian students of Physical Training and Sport University. Current Topics in Toxicology. 2013 9:21-26.

Pan, C.Y.; Chu, C.H.; Tsai, C.L.; Sung, M.C.; Huang, C.Y.; Ma, W.Y. The impacts of physical activity intervention on physical and cognitive outcomes in children with autism spectrum disorder. Autism 2016, 21, 190-202. https://doi.org/10.1177/1362361316633562

Patti A, Bianco A, Karsten B, Montalto MA, Battaglia G, et al. The effects of physical training without equipment on pain perception and balance in the elderly: A randomized controlled trial. Work 2017. 57:23-30. https://doi.org/10.3233/WOR-172539 
Pomara, C., Barone, R., Marino Gammazza, A., Sangiorgi, C., Barone, F., Pitruzzella, A., et al. (2016). Effects of Nandrolone Stimulation on Testosterone Biosynthesis in Leydig Cells. J. Cell. Physiol. https://doi.org/10.1002/jcp.25272

Pomara, C., D'Errico, S., Riezzo, I. et al. Sudden cardiac death in a child affected by Prader-Willi syndrome. Int J Legal Med 119, 153-157 (2005). https://doi.org/10.1007/s00414-004-0513-9

Pomara, C., Neri, M., Bello, S., Fiore, C., Riezzo, I., and Turillazzi, E. (2014). Neurotoxicity by Synthetic Androgen Steroids: Oxidative Stress, Apoptosis, and Neuropathology: A Review. Curr. Neuropharmacol. https://doi.org/10.2174/1570159X13666141210221434

Tyler, C.V.; Schramm, S.C.; Karafa, M.; Tang, A.S.; Jain, A.K. Chronic Disease Risks in Young Adults with Autism Spectrum Disorder: Forewarned Is Forearmed. Am. J. Intellect. Dev. Disabil. 2011, 116, 371-380. https://doi.org/10.1352/1944-7558-116.5.371

Sairanen M, Lucas G, Ernfors $P$, et al.: Brain-derived neurotrophic factor and antidepressant drugs have different but coordinated effects on neuronal turnover, proliferation, and survival in the adult dentate gyrus. J Neurosci, 2005, 25: 1089-1094. https://doi.org/10.1523/JNEUROSCl.3741-04.2005

Sorensen, C.; Zarrett, N. Benefits of Physical Activity for Adolescents with Autism Spectrum Disorders: A Comprehensive Review. Rev. J. Autism Dev. Disord. 2014, 1, 344-353. https://doi.org/10.1007/s40489-014-0027-4

Ventura Spagnolo, E., Mondello, C., Di Mauro, D., Alibrandi, A., Rizzo, G. Analysis on sarcoglycans expression as markers of septic cardiomyopathy in sepsis-related death. 2018. International Journal of Legal Medicine. 132(6), pp. 1685-1692. https://doi.org/10.1007/s00414-018-1840-6

Wu, Y.D. Efects ofWater Sports on Behavior and Serum IL Level of Autistic Children; Guangzhou Sport University: Guangzhou, China, 2017.

Xue, S.Y. A Study on How Sports Skills Influence Children with Autism. Mod. Comm. 2019, 13, $209-210$. Yang, Y.; Yang, Y. Analysis on Efects of Sports Intervention on Children Autism. Chin. Mod. Med. 2016, 23, 29-31.

Zachor, D.A.; Vardi, S.; Baron-Eitan, S.; Brodai-Meir, I.; Ginossar, N.; Ben-Itzchak, E. The efectiveness of an outdoor adventure programme for young children with autism spectrum disorder: A controlled study. Dev. Med. Child. Neurol. 2017, 59, 550-556. https://doi.org/10.1111/dmcn.13337

Zhang, J.M.; Wang, S.B.; Ling, Q.J. Advances in research on the efects of physical activity on autism. Chin. J. Sports Med. 2017, 36, 552-557.

Zhang, J.; Yang, J.Q. Efects of Sports Intervention on Behaviors and Living Quality of Autistic Children. Chin. J. Clin. Res. 2017, 30, 1244-1246.

\section{@(@) $\Theta \Theta$}

This work is licensed under a Attribution-NonCommercial-NoDerivatives 4.0 International (CC BY-NC-ND 4.0). 